\title{
Divergência genética entre linhagens de melão e a heterose de seus híbridos.
}

\author{
Waldelice O. de Paiva \\ Embrapa Agroindústria Tropical, C. Postal 3761,60.511-110 Fortaleza-CE, E-mail walde@cnpat.embrapa.br
}

\section{RESUMO}

Avaliou-se a divergência genética entre linhagens e híbridos de melão e a heterose verificada nos híbridos produzidos com o cruzamento destas linhagens. O experimento foi desenvolvido de setembro a novembro/98, no Município de Pacajús (CE). Os tratamentos corresponderam a nove linhagens pertencentes aos grupos cantalupensis, inodorus e momordica e os dez híbridos obtidos pelo cruzamento dos seguintes tipos de linhagens: cantalupensis $\mathrm{x}$ cantalupensis, inodorus $\mathrm{x}$ inodorus, cantalupensis $\mathrm{x}$ momordica $\mathrm{e}$ inodorus x momordica. As maiores contribuições para a divergência genética entre as linhagens paternais foram observadas para sólidos solúveis totais e para o formato do fruto. Cucumis melo inodorus e C. melo cantalupensis formaram um único grupo. Nos híbridos, as distâncias genéticas foram maiores quando se utilizaram linhagem do grupo momordica como um dos parentais e menores, quando as duas linhagens eram cantalupensis. A heterose favorável nos híbridos nem sempre ocorreu quando se utilizaram linhagens divergentes, enquanto que cruzamentos entre linhagens com pequena distância genética manifestaram essa característica.

\section{ABSTRACT}

\section{Genetic divergence among melon lines and the heterosis in} their hybrids.

The genetic divergence in melon lines and hybrids was studied, besides the heterosis manifested in the hybrids produced from lines. The experiments were conducted from September to November/98, in Pacajus, Ceará (Brazil). The treatment consisted of nine lines of cantalupensis, inodorus and momordica groups and ten hybrids produced between cantalupensis $\mathrm{x}$ cantalupensis, inodorus $\mathrm{x}$ inodorus, cantalupensis x momordica, inodorus x momordica lines types. The best contribution for genetic divergence between lines was shown in total soluble solids and fruit shape. Cucumis melo inodorus and $C$. melo cantalupensis were grouped together. The highest genetic distance was verified in the hybrids produced with one parental momordica. The smallest genetic distance was observed when both parents were cantalupensis. Favorable heterosis in the hybrids was not always verified when the parents were divergent, whilst hybrids from lines closely related showed this characteristic.

\section{(Aceito para publicação em 29 de novembro de 2.001)}

$\mathrm{N}_{\mathrm{d}}^{\mathrm{a}}$ as espécies vegetais em que o produto comercial é utilizado na forma in natura os atributos de qualidade tornam-se determinantes para a sua aceitação pelos consumidores. No caso do melão, para não serem modificadas as características reconhecidamente aceitas no mercado, os híbridos são obtidos do cruzamento entre linhagens muito próximas e isso tem limitado a seleção de linhagens parentais (McCreight, 1993). Por esse motivo, informações resultantes do uso de genitores divergentes são escassas.

Os estudos da divergência genética têm sido de grande importância em programas de melhoramento envolvendo hibridações, pois sem a necessidade de cruzamentos, identificam progenitores que em futuros cruzamentos possibilitem maior efeito heterótico (Cruz et al., 1994). Com isto, é possível avaliar maior número de linhagens para maior número de características. É aplicado para diversas espécies vegetais como critério de seleção de genitores (Shamsuddin, 1985; Cruz et al.,1994).
Quando o objetivo do melhoramento não é produzir híbridos, o conhecimento da diversidade alélica ou gênica, constatada pelas estimativas da heterose ou através da distância genética em cruzamentos, pode auxiliar na escolha de métodos de seleção mais eficientes para explorar esta variabilidade recombinacional nas gerações avançadas.

O presente trabalho teve por objetivo avaliar a divergência genética de linhagens de melão e a heterose dos seus híbridos, em combinações previamente escolhidas.

\section{MATERIAL E MÉTODOS}

Utilizaram-se oito linhagens de melão pertencentes ao programa de melhoramento genético da Embrapa Agroindústria Tropical, obtidas após sete gerações de autofecundação, e uma linhagem considerada homozigota, introduzida da Universidade de Cornell, reconhecida como resistente ao vírus do mosaico do zucchini, vírus do mosaico da melancia e a afídeos (Pitrat, 1990). As linhagens da Embrapa Agroindústria
Tropical são IM 03.02; IM 03.04; IM 04.00; IM 05.00; IM 07.00; IM 47.00 (grupo cantalupensis, frutos redondos, epiderme rendilhada e amarela, polpa e placenta de cor salmão); IM 50.00 e IM 54.00 (grupo inodorus, frutos ovais, epiderme enrugada e amarelo-ouro, polpa e placenta de cor creme). A linhagem da Universidade de Cornell (PI 414723) pertencente ao grupo momordica, apresenta frutos compridos de epiderme lisa e amarela e polpa e placenta de cor salmão. Merece destaque a expressão sexual, do tipo monoico, da linhagem PI 414723, à semelhança da maioria das cultivares pertencentes ao grupo momordica (Robinson \& DeckerWalters, 1999), enquanto que as demais linhagens mostram expressão sexual andromonóica. Foram efetuados os cruzamentos direcionados: linhagens com características de frutos semelhantes (cantalupensis $\mathrm{x}$ cantalupensis $\mathrm{e}$ inodorus $\mathrm{x}$ inodorus) e linhagens com características diferentes (cantalupensis $\mathrm{x}$ momordica e inodorus x momordica). Os dez híbridos obtidos foram avaliados juntamente com as nove linhagens 
Divergência genética entre linhagens de melão e a heterose de seus híbridos.

Tabela 1. Média de características agronômicas e de qualidade do fruto avaliadas nas linhagens de melão. Pacajus-CE, Embrapa Agroindústria Tropical, 1998.

\begin{tabular}{|c|c|c|c|c|c|c|c|c|}
\hline Genótipos & NFP1/ & PFP & PMF & TCS & FF & TCC & DF & SST \\
\hline IM 03.02 & $2,09 a b^{2)}$ & $1,63 a$ & $0,77 a$ & $5,68 d$ & $1,22 a b$ & $17,41 a$ & $0,59 a$ & $9,55 a b$ \\
\hline IM 03.04 & $1,07 a$ & $0,82 a$ & $0,77 a$ & $6,22 \mathrm{de}$ & $1,01 a$ & $48,08 a$ & $0,79 a$ & $5,77 a$ \\
\hline IM 04.00 & $1,86 a b$ & $1,81 a$ & $0,62 a$ & $5,12 b c$ & $1,12 a b$ & $40,32 a$ & $0,68 a$ & $10,66 b c$ \\
\hline IM 05.00 & $1,76 a$ & $1,30 a$ & $0,70 a$ & $5,75 d$ & $1,06 a b$ & $29,81 a$ & $0,70 a$ & $8,99 b$ \\
\hline IM 07.00 & $1,30 a$ & $1,16 a$ & $1,12 a$ & $6,17 \mathrm{de}$ & $1,29 b$ & $19,55 a$ & $0,70 a$ & $10,72 b c$ \\
\hline IM47.00 & $1,86 a b$ & $1,34 a$ & $0,69 a$ & $5,11 b c$ & $1,11 a b$ & $31,14 a$ & $0,88 a$ & $8,94 b$ \\
\hline IM50.00 & $2,08 a b$ & $1,10 a$ & $0,52 a$ & $4,09 a$ & $1,05 a b$ & $19,20 a$ & $1,19 a$ & $12,11 \mathrm{c}$ \\
\hline IM54.00 & $2,75 a b$ & $2,17 a$ & $0,81 a$ & $6,45 \mathrm{e}$ & $1,02 a$ & $38,01 a$ & $0,63 a$ & $10,08 \mathrm{bc}$ \\
\hline PI 414723 & $3,05 b$ & $2,56 a$ & $0,89 a$ & $4,87 \mathrm{~b}$ & $2,12 \mathrm{c}$ & $40,59 a$ & $0,80 a$ & $5,33 a$ \\
\hline
\end{tabular}

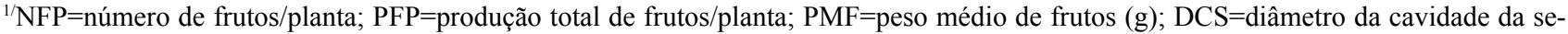
mente $(\mathrm{cm}) ; \mathrm{FF}=$ formato do fruto; TCC=taxa de concentração da colheita $(\%) ; \mathrm{DF}=$ densidade do fruto; $\mathrm{SST}=$ sólidos solúveis totais $\left({ }^{\circ} \mathrm{Brix}\right)$. Médias seguidas de mesma letra não diferem entre sí ao nível de 5\% pelo teste de Tukey.

parentais em um experimento instalado sob delineamento de blocos ao acaso, com três repetições e dez plantas por parcela. O experimento foi conduzido no período de setembro a novembro/98, em campo, na Estação Experimental de Pacajus (CE), pertencente à Embrapa Agroindústria Tropical. As distâncias entre linhas de plantio e entre plantas dentro da linha foram respectivamente de 2,00 e 0,50 metros. O cultivo foi conduzido sob irrigação por gotejamento e o manejo seguiu as indicações do sistema de produção para a cultura (Dusi, 1992).

Foram avaliados o número e peso total de frutos por planta, taxa de concentração da colheita aos 70 dias póssemeadura em relação à produção total e peso médio dos frutos. Em nove frutos de cada tratamento foram obtidas as medidas do formato (relação entre os diâmetros externo longitudinal e transversal) e da cavidade da semente (diâmetro transversal interno). A densidade do fruto foi estimada pela relação entre o volume e o peso, sendo o volume, calculado pela quantidade de água que um fruto desloca quando colocado dentro de um vasilhame graduado. O teor de sólidos solúveis totais foi determinado em uma amostra de suco homogeneizado, extraído de uma fatia longitudinal, com uso de um refratrômetro de campo. Antes de se efetuarem as análises estatísticas os parâmetros número de frutos e o índice do formato, foram transformados para $\sqrt{x+1}$, seguindo a metodologia de Steel \& Torrie (1960). Com os dados obtidos efetuaram-se as análises gené- tico-estatísticas utilizando-se o programa computacional Genes (Cruz, 1997). As heteroses, em relação à média dos pais $\left(\mathrm{H}_{\mathrm{mp}} ; \mathrm{mp}=100\right)$ foram expressas em porcentagem (acréscimo ou decréscimo) do valor médio observado para as linhagens parentais. A divergência genética entre os progenitores foi quantificada pela distância generalizada de Mahalanobis $\left(\mathrm{D}^{2}\right)$, e a delimitação dos grupos de similaridade foi calculada seguindo a metodologia proposta por Tocher (RAO, 1952).

\section{RESULTADOS E DISCUSSÃO}

As análises de variância para as oito características avaliadas, indicam que existem diferenças estatísticas significativas entre os genótipos para número de frutos por planta (NFP), peso total de frutos por planta (PFP), peso médio de frutos (PMF), diâmetro da cavidade da semente (DCS), formato do fruto (FF) e sólidos solúveis totais (SST). Efetuados os desdobramentos dos efeitos de tratamentos, verificou-se que as linhagens diferem para NFP, PMF, DCS, FF e SST, enquanto que os híbridos mostram diferenças para NFP, PMF, DCS, FF e SST. Observa-se que ocorreram valores elevados para os coeficientes de variação ambiental de PFP e taxa de concentração da colheita (TCC) indicando que a colheita concentrada e a produção de frutos sofrem com as modificações ambientais. Estes valores estão coerentes com o comportamento do meloeiro, que é muito afetado pelo am- biente, mostrando grande variabilidade ambiental dentro de cultivares (Davis et al., 1964; Nelson \& Burguer, 1996) e mesmo entre plantas dentro de cultivares.

Os testes de médias das linhagens (Tabela 1) evidenciaram que a linhagem do grupo momordica, difere para NFP e FF, e é semelhante a IM 03.04 no que se refere aos baixos teores de sólidos solúveis totais. Estas linhagens já haviam sido anteriormente avaliadas, confirmando desempenho de PI 414723 para alta produção de frutos e de IM 03.04 em produzir frutos com baixos teores de açúcares (Paiva et al., 2000). Constata-se que baixo teor de açúcares é uma característica inerente desta linhagem, apesar de pertencer ao grupo cantalupensis, cujos frutos mostram altos valores para SST.

A contribuição relativa dos teores de sólidos solúveis totais para a divergência genética é muito grande $(38,39 \%)$, sendo a característica que contribui mais fortemente para a divergência, seguida pelo formato do fruto $(31,16 \%)$. Juntas, essas duas características alcançaram quase $70 \%$ da variação total. O fato do sólidos solúveis totais mostrar alta contribuição para a divergência genética é indicativo de que linhagens com atributos qualitativos excepcionais, mas com baixo teor de sólidos solúveis não devem ser descartadas para a obtenção de híbridos, haja vista que, de acordo com Moonsoon et al. (1996), ocorre heterose favorável para essa característica. As características DCS, NFP, PMF, Den- 
Tabela 2. Estimativas da divergência genética entre pares de linhagens de melão, expressas pela distância generalizada de Mahalanobis $\left(\mathrm{D}^{2}\right)$, e das heteroses $(\mathrm{H} \%)$ e médias $(\mathrm{X})$ dos híbridos referentes às características agronômicas e de qualidade do fruto e as respectivas correlações. Pacajus (CE), Embrapa Agroindústria Tropical, 1998.

\begin{tabular}{|c|c|c|c|c|c|c|c|c|c|c|c|c|c|c|c|c|c|}
\hline \multirow{2}{*}{ Genitores } & \multirow{2}{*}{ D2 } & \multicolumn{2}{|c|}{ NFP } & \multicolumn{2}{|c|}{ PFP } & \multicolumn{2}{|c|}{ PMF } & \multicolumn{2}{|c|}{ DCS } & \multicolumn{2}{|c|}{ FF } & \multicolumn{2}{|c|}{ TCC } & \multicolumn{2}{|c|}{ DF } & \multicolumn{2}{|c|}{ SST } \\
\hline & & X1) & H (\%) & $x$ & $H(\%)$ & $x$ & $\mathrm{H}(\%)$ & $x$ & $H(\%)$ & $x$ & $\mathrm{H}(\%)$ & $x$ & $H(\%)$ & $x$ & $\mathrm{H}(\%)$ & $x$ & $\mathrm{H}(\%)$ \\
\hline $1 \times 9$ & 107,18 & $2,5^{a b}$ & $-2,7$ & $4,12^{a}$ & 101,1 & $1,65^{b}$ & 98,08 & $6,26^{\mathrm{b}}$ & 18,56 & $1,86^{c}$ & 10,92 & $33,64^{a}$ & 15,99 & $0,75^{a}$ & 7,06 & $8,35^{a b}$ & 12,25 \\
\hline $1 \times 4$ & 5,35 & $3,9^{b c}$ & 102,1 & $2,15^{a}$ & 46,81 & $0,55^{a}$ & $-25,0$ & $4,68^{a}$ & $-14,9$ & $1,15^{a}$ & 0,67 & $17,42^{\mathrm{a}}$ & $-26,2$ & $0,85^{a}$ & 30,32 & $11,75^{\mathrm{c}}$ & 26,71 \\
\hline $2 \times 9$ & 133,05 & $5,23^{c}$ & $-16,07$ & $5,38^{a}$ & $-22,9$ & $1,03^{a}$ & $-8,02$ & $5,93^{a b}$ & $-8,64$ & $1,53^{b}$ & $-2,38$ & $51,31^{a}$ & 68,64 & $0,70^{a}$ & 3,55 & $6,73^{a}$ & 3,04 \\
\hline $2 \times 5$ & 45,19 & $1,07^{a}$ & $-2,37$ & $1,73^{a}$ & 41,5 & $1,41^{\mathrm{a}}$ & 40,63 & $6,51^{b c}$ & 10,67 & $1,05^{a}$ & 29,12 & $30,48^{a}$ & 24,41 & $0,63^{a}$ & 0,13 & $7,89 a b$ & 2,33 \\
\hline $3 \times 9$ & 146,14 & $2,4^{a b}$ & 13,71 & $2,58^{a}$ & 50,7 & $1,07^{\mathrm{a}}$ & 32,80 & $5,53^{a b}$ & 11,53 & $2,09^{c}$ & 4,74 & $50,33^{a}$ & $-29,9$ & $0,74^{\text {a }}$ & $-22,18$ & 8,19 ab & $-12,13$ \\
\hline $3 \times 6$ & 6,32 & $1,57^{a b}$ & $-55,58$ & $0,97^{a}$ & $-22,6$ & $0,60^{a}$ & 69,22 & $4,77^{a}$ & 72,78 & $1,09^{a}$ & $-33,8$ & $60,24^{a}$ & 32,80 & $0,81^{a}$ & $-37,76$ & $10,11^{\mathrm{pc}}$ & 36,94 \\
\hline $7 \times 9$ & 211,93 & $1,14^{a}$ & 36,07 & $1,38^{a}$ & 61,32 & $1,19^{a}$ & 17,56 & $7,75^{c}$ & 5,74 & $1,05^{a}$ & 4,71 & $39,73^{a}$ & $-23,4$ & $0,62^{a}$ & $-33,38$ & 11,94 & $-9,39$ \\
\hline $7 \times 8$ & 43,84 & $2,75^{a b}$ & 10,59 & $2,46^{a}$ & 68,51 & $0,88^{a}$ & 72,89 & $5,88^{a b}$ & 14,17 & $1,09^{a}$ & 32,98 & $20,07^{a}$ & $-31,9$ & $0,71^{a}$ & 5,17 & $9,74^{b c}$ & 23,99 \\
\hline $8 \times 9$ & 155,40 & $2,59 a b$ & 48,17 & $3,90^{a}$ & 5,49 & $1,47^{a}$ & 70,12 & $6,46^{\mathrm{b}}$ & 17,32 & $2,09^{c}$ & $-32,8$ & $26,73^{a}$ & $-31,2$ & $0,75^{a}$ & $-22,09$ & $9,55^{\mathrm{b}}$ & 41,98 \\
\hline $8 \times 7$ & 43,84 & $3,29^{b}$ & 154,2 & $2,64^{a}$ & 227,3 & $0,78^{\text {a }}$ & 23,87 & $5,57^{\mathrm{ab}}$ & 6,71 & $1,09^{a}$ & $-2,06$ & $21,92^{\mathrm{a}}$ & 15,73 & $0,61^{\text {a }}$ & $-11,62$ & $10,05^{c}$ & 21,20 \\
\hline Corr. Pears & son & & $-0,20$ & & 0,63 & & 0,17 & & 0,76 & & 0,06 & & 0,20 & & $-0,29$ & & 0,33 \\
\hline Corr. Spenc & cer & & $-0,37$ & & 0,70 & & 0,16 & & 0,71 & & 0,14 & & 0,08 & & $-0,26$ & & 0,28 \\
\hline
\end{tabular}

${ }^{1 / \mathrm{NFP}}=$ número de frutos; $\mathrm{PFP}=$ produção total $(\mathrm{g} /$ planta $) ; \mathrm{PMF}=$ peso médio de frutos $(\mathrm{g}), \mathrm{DCS}=$ diâmetro da cavidade da semente $(\mathrm{cm})$, $\mathrm{FF}=$ formato do fruto; $\mathrm{TCC}=$ taxa de concentração da colheita; $\mathrm{DF}=$ densidade do fruto; $\mathrm{SST}=$ sólidos solúveis totais $\left({ }^{\circ} \mathrm{Brix}\right)$ )

Médias seguidas de mesma letra não diferem entre sí ao nível de 5\% pelo teste de Tukey.

sidade do fruto (DF), TCC e PFP apresentaram contribuição relativa de 9,15 ; 7,58; 7,06; 3,58; 2,38 e $0,67 \%$.

As médias de dissimilaridade entre cada par de genótipos obtidas pela distância generalizada de Mahalanobis $\left(\mathrm{D}^{2}\right)$, permitiram a formação de dois grupos de similaridade. O grupo I foi composto pelas oito linhagens da Embrapa Agroindústria Tropical, embora apresentem diferenças para tipo de fruto e grupo botânico. É provável que se fossem utilizadas também nesta avaliação as características de tipo de superfície de epiderme, coloração da epiderme, coloração da polpa, que são mais contratantes, o resultado do agrupamento seria diferente. O outro grupo é formado apenas por PI 414723, que é o mais divergente.

As distâncias genéticas, calculadas pelo método de Mahalanobis, foram maiores quando se utilizava a linhagem do grupo momordica como um dos parentais, e menores quando duas linhagens eram do grupo cantalupensis (Tabela 2). O cruzamento mais divergente foi verificado entre uma linhagem inodorus e outra momordica $(7 \times 9=211,93)$. Hierarquizando-se as médias das características, do ponto de vista comercial, verifica-se que esse cruzamento ( $7 \times 9)$, ocuparia o $9^{\circ}$ lugar para NFP e PFP, o $4^{\circ}$ lugar para PMF, o $10^{\circ}$ lugar para DCS, o $8^{\circ}$ lugar para $\mathrm{FF}$ o $4^{\circ}$ lugar para TCC e o primeiro lugar para SST.
Os resultados obtidos confirmam que esse germoplasma não é adequado para ser utilizado diretamente na produção de híbridos porque resulta em frutos com comprimento acima do desejável, e densidade da polpa muito baixa, características de frutos com pequena espessura de polpa. Contudo esses híbridos podem ser recombinados para sintetizar uma população onde os atributos favoráveis de resistência às doenças, precocidade e concentração de colheita possam ser explorados. Observase, ainda que a heterose para SST nestes cruzamentos foi positiva em duas ocasiões, quando se cruzou com IM 03.02, uma linhagem cantaloupe (cantalupensis) e quando se utilizou IM 40.00, uma linhagem amarela (inodorus). Considerando que sólidos solúveis totais é uma característica que tem controle poligênico, com ação genética aditiva e não aditiva e heterose (McCreiht et al.,1993), existe a possibilidade de que num programa de seleção recorrente esta característica seja melhorada, com possibilidades de obter altos ganhos na seleção.

Observa-se também na Tabela 2, que a combinação de progenitores distantes, considerados divergentes, nem sempre resulta em heterose expressiva nos híbridos. Valores de heterose abaixo de $10 \%$ foram observados nos seguintes cruzamentos: $1 X 9$, para NFP; $2 X 9$, para PMF, TCS, DF, e SST; 3X9, para
FF,TCS, e SST. Por outro lado, os maiores valores positivos para a heterose foram observados nas combinações para NFP e PFP, no cruzamento entre duas linhagens do grupo inodorus (8X7), com valores de heterose de $154,24 \%$ e $227,38 \%$; para PMF, no cruzamento entre uma linhagem cantalupensis e outra momordica (1x9), com heterose de $98,08 \%$; para TCC, no cruzamento entre uma linhagem cantalupensis e outra momordica $(2 \times 9)$ com heterose de $68,64 \%$; para DF, no cruzamento entre duas linhagens cantalupensis $(1 \mathrm{x} 4)$, com heterose de $30,32 \%$; e para SST, no cruzamento entre uma linhagem do grupo inodorus e outra momordica ( 8 X9), com heterose de $41,98 \%$.

De acordo com Cruz et al. (1994), em milho devem ser evitados cruzamentos entre cultivares do mesmo padrão de similaridade, para maximizar a variabilidade indispensável em qualquer programa de melhoramento. O que se verificou nesse trabalho, é que a heterose se manifesta mesmo em híbridos produzidos com linhagens cuja distância genética é bastante reduzida, a exemplo do cruzamento $1 \mathrm{X} 4$ ou $3 \mathrm{X} 6$, efetuado entre duas linhagens do grupo cantalupensis. Resultados semelhantes já foram relatados em quiabo por Parpat et al., (1980).

Como a heterose é uma medida relativa da geração $\mathrm{F}_{1}$, em comparação à mé- 
dia dos pais Cruz et al., (1994) sugerem que na escolha dos genitores devem ser considerados, além da divergência genética, seus próprios desempenhos, concordando com a maneira como até então são formados os híbridos de melão.

Apesar da correlação entre a divergência genética dos progenitores e o desempenho médio dos híbridos ter sido positiva para a maioria dos caracteres, também foram detectadas correlações negativas, no caso dos pais e das médias de híbridos para os caracteres de NFP e DF. Pelo que se conhece, no que se refere ao número de frutos por planta, a ineficiência da predição deste caráter pode ser atribuída aos efeitos genéticos não aditivos (McGreicht et al., 1993).

\section{AGRADECIMENTOS}

Ao Conselho Nacional de Desenvolvimento Científico e Tecnológico (CNPq); Programa de Biotecnologia para a Competitividade Agrícola
(BIOEX); Programa de Apoio ao Desenvolvimento da Fruticultura Irrigada do Nordeste (PADFIN), e à VALEFRUTAS-Associação para o Desenvolvimento do Agronegócio do Vale do Assu pelos recursos fornecidos.

\section{LITERATURA CITADA}

CRUZ, C.D. Programa GENES: Aplicativo Computacional em Genética e Estatística. Viçosa: UFV, 1997. 442 p.

CRUZ, C.D.; CARVALHO, S.P.; VENCOVSKY,

R. Estudos sobre a divergência genética II. Eficiência da predição do comportamento de híbridos com base na divergência de progenitores. Revista Ceres, Viçosa, v. 41, p. 183-194, 1994.

DAVIS, R.M.; BACKER, G.A.J.; KASMIRE, R.F. Muskmelon quality characteristics- their variability and interrelationsships. Hilgardia v. 35, p. 479, 1964.

DUSI, A.N. Melão para exportação: aspectos técnicos da produção. Brasília: DENACOOP, 1992. $37 \mathrm{p}$.

McCREIGHT, J.D.; NERSON, H.; FRUMET, R. Melon Cucumis melo L. in: G. KALLOO; BERG, B.O. Ed. Genetic Improvement of vegetable Crops. 1993, $530 \mathrm{p}$.
MOOSOON, K.; YONGKWON, K.; HEEDON, C. Combining ability of fruit yield and quantitative charaters in muskmelon (Cucumis melo L). Journal of Korean Society for Horticultural Science. v. 37, p. 677-661, 1996.

NELSON, H.; BURGUER, Y. Parental characteristics limit yield and quality of wintergrow galia-type muskmelon. Journal of Genetics \& Breeding v. 50, n. 1, p. 61-66, 1996.

PAIVA, W.O; NETO, H.S.; LOPES, A.G.S. Avaliação de linhagens de melão. Horticultura Brasileira, Brasília, v.18, n. 2, p. 109-113, 2000.

PITRAT, M. Gene list for Cucumis melo L. Cucurbit Genetic Cooperative, Maryland, v. 13, p. 58-60, 1990

RAO, R.C. Advanced statistical methods in biometrical research. New York, John Willey and Sons, 1952. $390 \mathrm{p}$.

ROBINSON, R.W.; DECKER-WALTERS, D.S. Cucurbits. CAB, International, Oxford, UK, 1999. 226 p.

PARPAT, P.S.; DHANKHAR, B.S.; PANDITA, M.L.; DUDI, B.S. Genetic divergence in parents and their hibrids in okra (Albelmoschus esculentus (L) Moench. Genetic Agriculture, v. 34, p. 323330, 1980.

SHAMSUDDIN, A.S.M. Genetic diversity in relation to heterosis and combining ability in spring wheat. Theoretical and Applied Genetic, Berlin, v. 70, p. 306-308, 1985.

STEEL, R.G.D.; TORRIE, J.H. Principle and Procedures of Statistics. McGraw-Hill, New York, 1960. 633 p. 